\title{
A general method to fine-tune fluorophores for live-cell and in vivo imaging
}

Jonathan B. Grimm, Anand K. Muthusamy, Yajie Liang, Timothy A. Brown, William C. Lemon, Ronak Patel, Rongwen Lu, John J. Macklin, Phillip J. Keller, Na Ji, and Luke D. Lavis*

Janelia Research Campus, Howard Hughes Medical Institute, Ashburn, VA, USA

*Corresponding author: lavisl@janelia.hhmi.org 


\section{Abstract}

Pushing the frontier of fluorescence microscopy requires the design of enhanced fluorophores with finely tuned properties. We recently discovered that incorporation of four-membered azetidine rings into classic fluorophore structures elicits substantial increases in brightness and photostability, resulting in the 'Janelia Fluor' (JF) series of dyes. Here, we refine and extend this strategy, showing that incorporation of 3-substituted azetidine groups allows rational tuning of the spectral and chemical properties with unprecedented precision. This strategy yields a palette of new fluorescent and fluorogenic labels with excitation ranging from blue to the far-red with utility in live cells, tissue, and animals. 


\section{INTRODUCTION}

Small molecule fluorophores are essential tools for biochemical and biological imaging ${ }^{1,2}$. The development of new labeling strategies ${ }^{3}$ and innovative microscopy techniques ${ }^{4}$ is driving the need for new fluorophores with specific properties. A particularly useful class of dyes is the rhodamines, first reported in $1887^{5}$, and now used extensively due to the superb brightness and excellent photostability of this fluorophore scaffold ${ }^{1,2,6}$. The photophysical and chemical properties of rhodamines can be modified through chemical substitution ${ }^{6-13}$, allowing the creation of fluorescent and fluorogenic labels, indicators, and stains in different colors ${ }^{7,11-18}$.

Despite a century of work on this dye class, the design and synthesis of new rhodamines remains severely limited by chemistry. The classic method of rhodamine synthesis - acid catalyzed condensation ${ }^{2,5,6}$ - is incompatible with all but the simplest functional groups. To remedy this longstanding problem, our laboratory developed a strategy to synthesize rhodamine dyes using a Pd-catalyzed cross-coupling approach starting from simple fluorescein derivatives ${ }^{19}$. This approach facilitated the discovery of a novel class of dyes containing fourmembered azetidine rings, which elicit substantial increases in the quantum yield relative to classic rhodamines containing $N, N$-dimethylamino groups ${ }^{13}$. Three first-generation azetidine dyes include the rhodamine-based 'Janelia Fluor' 549 (JF 549,1 , Fig. 1a), carborhodamine Janelia Fluor $608\left(\mathrm{JF}_{608}, 2\right)$, and Si-rhodamine Janelia Fluor $646\left(\mathrm{JF}_{646}, 3\right)$. The enhanced brightness and photostability of these dyes makes them exceptionally useful labels for single-molecule experiments in vitro ${ }^{20}$ and in living cells ${ }^{13,21-24}$.

Although the Janelia Fluor dyes find broad use in cellular imaging ${ }^{21-24}$, it would be advantageous to develop methods to fine-tune the spectral and chemical properties of these dyes. The parent azetidinyl-rhodamine Janelia Fluor $549\left(\mathrm{JF}_{549}, 1\right.$; Fig. 1a) absorbs green light 
$\left(\lambda_{\max } / \lambda_{\mathrm{em}}=549 \mathrm{~nm} / 571 \mathrm{~nm}, \Phi=0.88\right)$ but is less suited for shorter excitation wavelengths.

Replacing the xanthene oxygen in $\mathrm{JF}_{549}(\mathbf{1})$ with quaternary carbon yields $\mathrm{JF}_{608}$ (2) with a 59-nm shift in spectral properties $\left(\lambda_{\max } / \lambda_{\mathrm{em}}=608 \mathrm{~nm} / 631 \mathrm{~nm}, \Phi=0.67\right)$ - suboptimal for common orange excitation sources centered at 589 or $594 \mathrm{~nm}$. Finally, inclusion of a silicon atom yields $\mathrm{JF}_{646}(3)$ with a $97-\mathrm{nm}$ shift in spectra $\left(\lambda_{\max } / \lambda_{\mathrm{em}}=646 \mathrm{~nm} / 664 \mathrm{~nm}, \Phi=0.54\right)$. This dye is well matched for excitation with common far-red laser lines (e.g., $647 \mathrm{~nm})$, although excitation with $633 \mathrm{~nm}$ light is less efficient. Overall, the ability to precisely adjust $\lambda_{\max }$ of rhodamine dyes could enable better matching of fluorophores with common excitation sources and filter sets.

In addition to $\lambda_{\max }$ and $\lambda_{\mathrm{em}}$, another critical property of rhodamine dyes is the equilibrium between the colorless, 'closed' lactone (L) form and the colored, fluorescent, 'open' zwitterionic (Z) form (Fig. 1a). Both $\operatorname{JF}_{549}\left(\mathbf{1}, \varepsilon=1.01 \times 10^{5} \mathrm{M}^{-1} \mathrm{~cm}^{-1}\right)$ and $\operatorname{JF}_{608}\left(\mathbf{2}, \varepsilon=9.9 \times 10^{4} \mathrm{M}^{-1} \mathrm{~cm}^{-1}\right)$ primarily adopt the open form in water as evidenced by their high absorptivity. In contrast, $\mathrm{JF}_{646}$ (3) predominantly adopts the colorless lactone form in solution $\left(\varepsilon=5.0 \times 10^{3} \mathrm{M}^{-1} \mathrm{~cm}^{-1}\right)$. Likewise, the free $\mathrm{JF}_{646}-\mathrm{HaloTag}^{25}$ ligand (4) is primarily in the colorless, lipophilic lactone form in aqueous solution, which renders it highly cell permeable (Fig. 1b). The binding of HaloTag ligand 4 to its cognate protein shifts the $\mathrm{L}-\mathrm{Z}$ equilibrium to the fluorescent form with a modest on:off absorbance ratio $=21(\text { Fig. 1b })^{13}$. Thus, structural modifications that shift the L-Z equilibrium could be used to improve both the cell permeability and fluorogenicity of labeling with $\mathrm{JF}_{646}$ and other rhodamine fluorophores.

Here, we describe a general method to finely tune the spectral and chemical properties of rhodamine dyes with unprecedented precision. The use of 3-substituted azetidines on the Janelia Fluor scaffold allows modulation of $\lambda_{\max }, \lambda_{\mathrm{em}}$, and the $\mathrm{L}-\mathrm{Z}$ equilibrium without affecting fluorescence quantum yield. The shifts in chemical and spectral properties can be explained 
using physical organic chemistry principles and quantum mechanical calculations. The structureactivity relationships are generalizable to rhodols, carborhodamines, and Si-rhodamine derivatives, allowing the rational design of improved fluorescent and fluorogenic labels across the visible spectrum.

\section{RESULTS}

Synthesis of rhodamines with 3-substituted azetidine groups. We reasoned we could tune the physicochemical properties of $\mathrm{JF}_{549}$ (1) by exploring different substitution patterns on the azetidine ring. Indeed, the azetidinyl-rhodamine system provides an ideal test case for N-substituent effects due to the following: (1) the high-yielding Pd-catalyzed cross-coupling synthesis $^{19}$, (2) the commercial availability of assorted 3-substituted azetidines, (3) the short, three-bond separation between the substituent and the rhodamine aniline nitrogen, and (4) the symmetry of the system. We hypothesized that electron withdrawing groups would decrease the $\lambda_{\max }$ of the fluorophore and also shift the $\mathrm{L}-\mathrm{Z}$ equilibrium towards the closed, colorless form lactone based on reports of fluoroalkane-substituted rhodamine dyes ${ }^{17,26}$.

To test these predictions, we synthesized compounds 5-12 from fluorescein ditriflate (13) using Pd-catalyzed cross-coupling (Table 1). We then evaluated the photophysical properties of compounds 5-12 in aqueous solution, comparing them to $\mathrm{JF}_{549}(\mathbf{1}$; Table 1). All of the substituted azetidinyl dyes were synthesized in good yield and showed high $\varepsilon$ values above $1 \times$ $10^{5} \mathrm{M}^{-1} \mathrm{~cm}^{-1}$. The lone exception was the 3,3-difluoroazetidine compound 12, which exhibited a slightly lower absorptivity $\left(\varepsilon=9.4 \times 10^{4} \mathrm{M}^{-1} \mathrm{~cm}^{-1}\right)$. Likewise, the quantum yield values of the azetidine dyes 5-12 were all $>0.80$ with the exception of the $N, N$-dimethyl-azetidin-3-amine compound $\mathbf{8}$, which showed $\Phi=0.57$ at $\mathrm{pH}$ 7.4. The quantum yield value for $\mathbf{8}$ is rescued at $\mathrm{pH}$ 
$5.0(\Phi=0.89$; Table 1), suggesting photoinduced electron transfer (PeT) quenching by the unprotonated dimethylamino groups ${ }^{27}$.

Although the $\varepsilon$ and $\Phi$ of the different azetidinyl rhodamine dyes was largely immune to substitution at the 3-position, the $\lambda_{\max }$ and $\lambda_{\mathrm{em}}$ values were strongly affected by the nature of the substituent (Table 1). Groups with greater electron-withdrawing character elicited larger hypsochromic shifts in $\lambda_{\max }$. This effect was additive. For example, the 3 -fluoroazetidinyl compound 10 showed a $13-\mathrm{nm}$ blue $\operatorname{shift}\left(\lambda_{\max }=536 \mathrm{~nm}\right)$ relative to the parent dye 1 and the 3,3difluoroazetidinyl-rhodamine (12) showed a further hypsochromic shift of $11 \mathrm{~nm}\left(\lambda_{\max }=525\right.$ $\mathrm{nm})$. We plotted $\lambda_{\max }$ against the available Hammett inductive substituent constants $\left(\sigma_{\mathrm{I}}\right)^{28}$ for the azetidine substituents in dyes 1, 5, and 8-12 and observed an excellent correlation (Fig. 1c), suggesting that the inductive effect of the substituents was primarily responsible for the decrease in absorption and emission maxima. The changes in $\lambda_{\max }$ were also observed in quantum mechanical calculations where the calculated $\lambda_{\max }$ values were within $5 \mathrm{~nm}$ of the experimental values (Fig. 1d).

We then determined the $K_{\mathrm{L}-\mathrm{Z}}$ for fluorophores $\mathbf{1 , 5}$, and 9-12 to examine the effect of the azetidine substituents on the lactone-zwitterion equilibrium ${ }^{29}$; values for compounds $\mathbf{6}-\mathbf{8}$ were not examined due to the ionizable substituents on the azetidine ring (Table 1). We determined these equilibrium values from the maximal extinction coefficients $\left(\varepsilon_{\max }\right)$ measured in acidic media (Methods). $\mathrm{JF}_{549}(\mathbf{1})$ and the 3,3-dimethylazetidinyl-rhodamine 5 showed $K_{\mathrm{L}-\mathrm{Z}}$ values $>3$, indicating that these dyes exist primarily in the open form. In contrast, the equilibrium of the 3,3difluoroazetidinyl rhodamine (12) was substantially smaller $\left(K_{\mathrm{L}-\mathrm{Z}}=0.068\right)$, showing that the electron-withdrawing fluorine substituents can shift the equilibrium toward the closed lactone form. The remainder of the dyes exhibited $K_{\mathrm{L}-\mathrm{Z}}$ values that were intermediate and trended with 
the electron-withdrawing character of the substituent (Table 1). Collectively, these results show that the $\lambda_{\max }$ and $\mathrm{L}-\mathrm{Z}$ equilibrium can be rationally tuned using different 3 -substituted azetidines without compromising fluorophore brightness.

Janelia Fluor 525. Rhodamine 12 exhibits $\lambda_{\max }$ at $525 \mathrm{~nm}$ and a high quantum yield $(\Phi=$ 0.91), making it a useful label for imaging with blue-green excitation (514-532 nm). Based on the $\lambda_{\max }$, we named this fluorophore 'Janelia Fluor 525 ' $\left(\mathrm{JF}_{525}\right)$ and prepared the $\mathrm{JF}_{525}-$ HaloTag ligand (14, Fig. 1f, Supplementary Note), which showed excellent labeling in live cells expressing HaloTag-histone H2B fusions (Fig. 1g). We hypothesized that the $\mathrm{JF}_{525}-$ HaloTag ligand (14) would show improved cell permeability relative to the analogous $\mathrm{JF}_{549}-$ HaloTag ligand (15, Fig. 1f) based on its higher propensity to adopt the lactone form (Table 1, Fig. 1e, Supplementary Fig. 1a). To test this hypothesis, we performed a pulse-chase experiment in live cells expressing HaloTag-histone $\mathrm{H} 2 \mathrm{~B}$ fusions pulsing with either $\mathrm{JF}_{525}-$ HaloTag ligand $\mathbf{1 4}$ or $\mathrm{JF}_{549}-$ HaloTag ligand 15 and chasing with the far-red $\mathrm{JF}_{646}$ ligand 4 (Fig. 1b). Compound 14 labeled intracellular proteins faster than $\mathrm{JF}_{549}$ ligand $\mathbf{1 5}$ (Fig. 1h). These results support the hypothesis that shifting the $\mathrm{L}-\mathrm{Z}$ equilibrium towards the lactone form can improve cell permeability and also validate $\mathrm{JF}_{525}$ as the first cell-permeable self-labeling tag ligand with an excitation maximum near $532 \mathrm{~nm}$.

Janelia Fluor 503. Since fluorine is the most electronegative atom, the difluoroazetidinecontaining $\mathrm{JF}_{525}(\mathbf{1 2})$ represents the tuning limit of the azetidinyl-rhodamines towards the blue region of the spectrum. To access shorter wavelength dyes, we turned to the rhodol scaffold, which remains an intriguing but underexplored dye class ${ }^{30}$. In previous work ${ }^{13}$ we synthesized an azetindinyl-rhodol 16 ('Janelia Fluor 519'), which exhibited $\lambda_{\max } / \lambda_{\mathrm{em}}=519 \mathrm{~nm} / 546 \mathrm{~nm}, \varepsilon=5.9 \times$ $10^{4} \mathrm{M}^{-1} \mathrm{~cm}^{-1}$, and $\Phi=0.85$ (Fig. 2a). Based on the data with $\mathrm{JF}_{525}(\mathbf{1 2}$, Table 1) we surmised 
that replacement of the azetidine substituent with a 3,3-difluoroazetidine could elicit a desirable $\sim 15 \mathrm{~nm}$ blue-shift to yield a dye with maximal absorption closer to $488 \mathrm{~nm}$.

To test this hypothesis, we synthesized the 3,3-difluoroazetidinyl-rhodol 25, which showed the expected blue-shifted spectra with $\lambda_{\max } / \lambda_{\mathrm{em}}=503 \mathrm{~nm} / 529 \mathrm{~nm}, \varepsilon=8.3 \times 10^{4} \mathrm{M}^{-1} \mathrm{~cm}^{-1}$, and $\Phi$ $=0.87$ (Fig. 2a); we named this compound 'Janelia Fluor 503' $\left(\mathrm{JF}_{503}\right)$. We then synthesized the $\mathrm{JF}_{503}-$ HaloTag ligand (18, Fig. 2b, Supplementary Note), which was an excellent label for histone H2B-HaloTag fusions live cells (Fig. 2c). We compared this novel label to two other 488-excitatable HaloTag ligands based on the classic rhodamine $110\left(\lambda_{\max } / \lambda_{\mathrm{em}}=497 \mathrm{~nm} / 520 \mathrm{~nm}\right.$; 19, Supplementary Fig. 1b) and the recently described $N, N^{\prime}$-bis(2,2,2-trifluoroethyl)rhodamine $\left(\lambda_{\max } / \lambda_{\mathrm{em}}=501 \mathrm{~nm} / 525 \mathrm{~nm} ; \mathbf{2 0} \text {, Supplementary Fig. 1b }\right)^{17}$. The cell-loading time course for all three dyes was similar (Supplementary Fig. 1c) but the $\mathrm{JF}_{503}$ ligand showed higher photostability than the other two dyes in live cells (Fig. 2d), consistent with previous reports comparing the photostability of rhodols to rhodamines ${ }^{30}$.

Janelia Fluor 585. In previous work we synthesized several carborhodamine compounds from carbofluorescein ditriflate $(\mathbf{2 1})^{11}$, including $\mathrm{JF}_{608}$ (2, Fig. 1a, Fig. 3a) ${ }^{13}$. We also discovered that carborhodamines generally exhibit a higher propensity to adopt the closed lactone form, which was observed with $\mathrm{JF}_{608}\left(K_{\mathrm{L}-\mathrm{Z}}\right.$ for $\left.\mathbf{2}=0.091\right)$. However, as noted above, $\mathrm{JF}_{608}$ exhibits a suboptimal $\lambda_{\max }$ and is not fluorogenic when used as a HaloTag label. We hypothesized that incorporation of 3,3-difluoroazetidine substituents into a carborhodamine structure could solve both problems. Based on the 3,3-difluoroazetidine compound 12 in the rhodamine series (Table 1), this modification was expected to elicit a blue-shift of approximately $24 \mathrm{~nm}$, bringing the $\lambda_{\max }$ closer to the desired excitation wavelengths $(e . g ., 589 \mathrm{~nm})$. We also predicted this modification would create a fluorogenic label, based on the higher propensity of carborhodamines to adopt the 
closed lactone form. ${ }^{11}$ We note previous efforts to shift the L-Z equilibrium of carborhodamines using direct halogenation on the xanthene ring system did produce a HaloTag ligand with modest fluorogenicity (on:off contrast $=9$ ) but also severely decreased quantum yield ${ }^{17}$. Based on the data from the rhodamine series (Table 1), we expected that substitution with fluorine atoms on the 3-position of azetidine would increase quantum yield.

To test these predictions we synthesized the 3,3-difluoroazetidinyl carborhodamine (22) from 21 using Pd-catalyzed cross-coupling (Fig. 3a). This dye showed the expected blue-shift in $\lambda_{\max }$ and $\lambda_{\mathrm{em}}$ showing $585 \mathrm{~nm}$ and $609 \mathrm{~nm}$, respectively. The $\Phi$ was also modestly higher than 2 at 0.78, consistent with the results of the rhodamine series (Table 1). Based on these properties the dye was named 'Janelia Fluor 585' $\left(\mathrm{JF}_{585}\right)$. However, unlike the 3,3-difluoroazetidine-substituted rhodamine analog $\mathbf{1 2}\left(\mathrm{JF}_{525}\right)$, which showed only a small decrease in $\varepsilon$ relative to parent dye $\mathbf{1}$ (Table 1), carborhodamine 22 exhibited low visible absorption in water $\left(\varepsilon=1.5 \times 10^{3} \mathrm{M}^{-1} \mathrm{~cm}^{-1}\right)$ and a $K_{\mathrm{L}-\mathrm{Z}}$ near zero (Fig. 3a). These data show that inclusion of the electron-withdrawing fluorine substituents into this structure is sufficient to shift the equilibrium to the colorless lactone form. Measurement of the extinction coefficient in acidic trifluoroethanol, which stabilizes the open form of the dye, gave maximal extinction coefficient values $\left(\varepsilon_{\max }\right)$ of $1.21 \times$ $10^{5} \mathrm{M}^{-1} \mathrm{~cm}^{-1}$ for fluorophore 2 and $1.56 \times 10^{5} \mathrm{M}^{-1} \mathrm{~cm}^{-1}$ for fluorophore 22 (Fig. 3a).

We prepared the $\mathrm{JF}_{608}-$ HaloTag ligand (23) and $\mathrm{JF}_{585}-$ HaloTag ligand (24, Fig. 3b) via Pdcatalyzed cross-coupling (Supplementary Note) ${ }^{11,19}$. To compare the utility and fluorogenicity of these new HaloTag ligands we first measured the absorbance of both $\mathbf{2 3}$ and $\mathbf{2 4}$ in the absence and presence of excess HaloTag protein. $\mathrm{JF}_{608}-$ HaloTag ligand (23) showed only an $11 \%$ increase in absorption upon reaction with the HaloTag protein (Fig. 3c). For $\mathrm{JF}_{585}-$ HaloTag ligand 24, however, the observed absorbance increase upon conjugation was substantially higher 
at 80-fold (Fig. 3d). This fluorogenic reaction enabled 'no wash' cellular imaging experiments: incubation of $\mathrm{JF}_{608}-$ HaloTag ligand $(\mathbf{2 3}, 250 \mathrm{nM})$ with cells expressing HaloTag-H2B showed excellent nuclear labeling but high background due to the fluorescence of the free ligand staining internal membrane structures (Fig. 3g). In contrast, cells that were incubated with $250 \mathrm{nM}$ of $\mathrm{JF}_{585}-$ HaloTag ligand 24 and imaged directly showed bright nuclei with low fluorescence background (Fig. 3h).

Janelia Fluor 635. Having success with rational design of the carborhodamine system, we then turned to the Si-rhodamine $\mathrm{JF}_{646}(\mathbf{3}, \text { Fig. 3a })^{13}$. Based on the rhodamine and carborhodamine data, we hypothesized that addition of a single fluorine atom on each azetidine ring would lower the absorptivity of the free dye, increase the chromogenicity of the labeling reaction, and cause a $\sim 13 \mathrm{~nm}$ hypochromic shift, thus attaining a $\lambda_{\max }$ near $633 \mathrm{~nm}$. Accordingly, we converted Si-fluorescein ditriflate (25) to the fluorinated derivative $\mathbf{2 6}$ (Fig. 3a), which showed $\lambda_{\text {max }} / \lambda_{\mathrm{em}}=635 \mathrm{~nm} / 652 \mathrm{~nm}$, a slightly higher $\Phi=0.56$ relative to $\mathrm{JF}_{646}(3)$, and an extremely low absorbance in water with an extinction coefficient value of approximately $400 \mathrm{M}^{-}$ ${ }^{1} \mathrm{~cm}^{-1}$ (Fig. 3a). Based on these data we gave this dye the moniker 'Janelia Fluor 635' $\left(\mathrm{JF}_{635}\right)$. Both $\mathrm{JF}_{646}(\mathbf{3})$ and $\mathrm{JF}_{635}(\mathbf{2 6})$ exhibit high extinction coefficient values in acidic media, with $\varepsilon_{\max }$ $=1.52 \times 10^{5} \mathrm{M}^{-1} \mathrm{~cm}^{-1}$ and $1.67 \times 10^{5} \mathrm{M}^{-1} \mathrm{~cm}^{-1}$, respectively (Fig. 3a).

Analogous to the experiments with $\mathrm{JF}_{608}$ and $\mathrm{JF}_{585}$, we prepared the $\mathrm{JF}_{635}-$ HaloTag ligand (27, Supplementary Note) and compared it to the $\mathrm{JF}_{646}$ ligand 4 (Fig. 3b). As mentioned previously, the $\mathrm{JF}_{646}-$ HaloTag ligand (4) shows a 21-fold increase in absorbance upon binding to the HaloTag protein (Fig. 3e). The shifted L-Z equilibrium observed for the free $\mathrm{JF}_{635}(\mathbf{2 6}$, Fig. 3a) is also seen in the HaloTag ligand 27, which shows exceptionally low background and a 113fold increase in absorbance upon conjugation (Fig. 3f). Both of these absorbance increases are 
much larger than the previously published SiTMR ligand 28, which shows a 6.7-fold increase in absorption upon reaction with the HaloTag protein (Supplementary Fig. 1d-e). These in vitro results were mirrored in no wash cellular imaging experiments, where we incubated $250 \mathrm{nM}$ of either $\mathrm{JF}_{646}$ ligand 4 (Fig. 3i), $\mathrm{JF}_{635}$ ligand 27 (Fig. 3j), or SiTMR ligand 28 (Supplementary Fig. 1f) with cells expressing histone H2B-HaloTag fusions. Cells labeled with either of the azetidinyl dyes (4 or 27) exhibited much lower nonspecific extranuclear fluorescence than the SiTMR compound 28. However, as expected from the in vitro data (Fig. 3e-f) the $\mathrm{JF}_{635}$ ligand 27 exhibited the highest contrast due to low fluorescence in the unbound state.

Applications in tissue and in vivo. The HaloTag ligands of Janelia Fluor 585 (24) and Janelia Fluor 635 (27) are small, cell permeable, and exhibit high fluorogenicity upon labeling. We were curious if these properties would make them useful for labeling in more complex biological environments such as tissue or whole animals. We first attempted labeling in living brain tissue from Drosophila larvae using the $\mathrm{JF}_{635}-$ HaloTag ligand (27) due to its far-red excitation (Fig. 3a) and high on:off ratio (Fig. 3f,j). Nervous system explants from Drosophila third instar larvae expressing the HaloTag protein in 'Basin' neurons were dissected, incubated briefly with $\mathrm{JF}_{635}-$ HaloTag ligand $(27 ; 1 \mu \mathrm{M}, 10 \mathrm{~min})$, and imaged using the SiMView lightsheet microscope ${ }^{31}$. The $\mathrm{JF}_{635}$ label exhibited consistent labeling throughout the living tissue and low nonspecific background staining (Fig. 4a,b), demonstrating its utility beyond simple cell culture.

We next evaluated the JF dyes in the brains of living mice. The $\mathrm{JF}_{585}-$ HaloTag ligand 24 was chosen based on its high fluorogenicity (Fig. 3d,h) and superior 2-photon fluorescence at 1100 nm excitation (Fig. 4c), which is sufficiently separated from GFP-based indicators such as GCaMP6 (2-photon $\left.\lambda_{\max }=940 \mathrm{~nm}\right)^{32}$ to allow multicolor imaging. Cytosolic HaloTag protein 
was co-expressed in layer 4 or layer 5 visual cortex (V1) neurons with GCaMP6s via viral transduction and the mice were fitted with a chronic cranial window (Methods). Injection of 100 nmol of HaloTag ligand 24 into the tail vein (intravenous, IV) showed the $\mathrm{JF}_{585}$ ligand was blood-brain barrier-permeable and gave measureable labeling in the brain within 5 minutes, peaking around 6 hours and lasting for nearly two weeks as measured by epifluorescence (Fig. 4d, Supplementary Fig. 2a). Intraperitoneal injection (IP) also showed effective delivery to the brain although the peak intensity was lower than IV administration (Fig. 4d). Under 2-photon imaging, we observed that the GCaMP6 and $\mathrm{JF}_{585}$ signals co-localized (Fig. 4e, Supplementary Video 1) and the labeling showed no significant effect on neuronal activity (Fig. 4f,g), establishing the utility of this fluorophore in vivo.

\section{Discussion}

Replacement of $N, N$-dialkyl groups in rhodamine dyes with azetidines greatly improves the quantum efficiency without greatly affecting other spectral and chemical properties. Here, we show the azetidine strategy is remarkably flexible — substitutions on the azetidine ring do not compromise the high quantum yield values of the Janelia Fluor dyes and allow fine-tuning of $\lambda_{\text {max }} / \lambda_{\text {em }}$ and the $\mathrm{L}-\mathrm{Z}$ equilibrium. This resulted in the development of $\mathrm{JF}_{525}(\mathbf{1 2})$ and its HaloTag ligand 14-the first ligand for self-labeling tags with absorption maximum near $532 \mathrm{~nm}$. The design principles we discovered are generalizable to analogous structures - rhodols, carborhodamines, and Si-rhodamines - allowing the rational design of finely-tuned fluorophores such as $\mathrm{JF}_{503}\left(\mathbf{1 7}\right.$, Fig. 2a), $\mathrm{JF}_{585}(\mathbf{2 2})$, and $\mathrm{JF}_{635}$ (26, Fig. 3a). Together with $\mathrm{JF}_{549}(\mathbf{1})$ and $\mathrm{JF}_{646}$ $(\mathbf{2} \text {, Fig. 1 })^{13}$, we have now described six dyes that span the visible region of the spectrum and match common excitation wavelengths for fluorescence microscopy. In addition to the HaloTag 
ligands described above, we also prepared the corresponding SNAP-tag ligands 29-32, which can label SNAP-tag fusion proteins inside live cells (Supplementary Fig. 2b-i). Importantly, the new HaloTag ligands derived from $\mathrm{JF}_{585}$ and $\mathrm{JF}_{635}$ show a high degree of chromogenicity and fluorogenicity (Fig. 3c-j), a critical parameter in advanced imaging experiments ${ }^{33}$. Of particular interest is the ability to deliver these two dyes to neural tissue in explants (Fig. 4a,b) or whole animals (Fig. 4d-g), which could allow the imaging of deeper structures in the brain or the in vivo assembly of semisynthetic indicators for monitoring cellular activity ${ }^{3}$.

Although we focused on the fluorine-substituted azetidines in this paper, the other substitutions (Table 1) could be exploited to prepare fluorophores for specific applications. For example, the carboxy groups in compounds $\mathbf{5}$ and $\mathbf{6}$ could serve as attachment sites for a variety of chemical modifiers to improve solubility ${ }^{7}$, quench unwanted triplet states $^{34}$, or allow the molecule to serve as a multivalent fluorescent cross-linker. The modest $\mathrm{pH}$ sensitivity and presence of the basic amine in compound $\mathbf{8}$ could allow it to function as a $\mathrm{pH}$ sensor or stain for lysosomes. The methoxy group on compound $\mathbf{9}$ could be elaborated to a polyethylene glycol (PEG) or other solubilizing group. Finally, the cyano group in compound $\mathbf{1 1}$ could be used in multimodal imaging regimes where both fluorescence and $\operatorname{Raman}^{35}$ modalities are used for imaging. In all, this general method to tune photophysical and chemical properties against a backdrop of high quantum yield will allow the precise design of many new fluorophores for specific, sophisticated biological imaging experiments in increasingly complex systems. 


\section{ACKNOWLEDGEMENTS}

We thank A. Berro and E. Schreiter (Janelia) for purified HaloTag protein, H. Choi (Janelia) for contributive discussions and a critical reading of the manuscript. This work was supported by the Howard Hughes Medical Institute.

\section{Author Contributions}

L.D.L. and J.B.G. conceived the project. J.B.G. and A.K.M. performed organic synthesis. J.B.G. and L.D.L performed 1-photon spectroscopy measurements. Y.J., R.L. and N.J. designed, performed, and analyzed mouse imaging experiments. W.C.L. and P.J.K. designed, performed, and analyzed larval explant imaging experiments. R.P. and J.J.M performed 1-photon spectroscopy measurements. L.D.L. wrote the paper with input from the other authors.

\section{COMPETING INTERESTS}

The authors declare competing interests: J.B.G. and L.D.L. have filed patent applications whose value may be affected by this publication.

\section{ONLINE METHODS}

Chemical synthesis. Methods for chemical synthesis and full characterization of all novel compounds can be found in the Supplementary Note.

UV-vis and fluorescence spectroscopy. Fluorescent and fluorogenic molecules for spectroscopy were prepared as stock solutions in DMSO and diluted such that the DMSO concentration did not exceed 1\% v/v. Spectroscopy was performed using 1-cm path length, 3.5$\mathrm{mL}$ quartz cuvettes or 1-cm path length, 1.0-mL quartz microcuvettes from Starna Cells. All 
measurements were taken at ambient temperature $\left(22 \pm 2{ }^{\circ} \mathrm{C}\right)$. Absorption spectra were recorded on a Cary Model 100 spectrometer (Agilent). Fluorescence spectra were recorded on a Cary Eclipse fluorometer (Varian). Maximum absorption wavelength $\left(\lambda_{\max }\right)$, extinction coefficient $(\varepsilon)$, and maximum emission wavelength $\left(\lambda_{\mathrm{em}}\right)$ were taken in $10 \mathrm{mM}$ HEPES, pH 7.3 buffer unless otherwise noted; reported values for $\varepsilon$ are averages $(n=3)$. Normalized spectra are shown for clarity.

Determination $\boldsymbol{K}_{\mathbf{L}-\mathbf{Z}}$ and $\boldsymbol{\varepsilon}_{\mathbf{m a x}}$. To determine $K_{\mathrm{L}-\mathrm{Z}}$ we first performed dioxane- $\mathrm{H}_{2} \mathrm{O}$ titrations in spectral grade dioxane (Aldrich) and milliQ $\mathrm{H}_{2} \mathrm{O}$ (Supplementary Fig. 1a). The solvent mixtures contained $0.01 \% \mathrm{v} / \mathrm{v}$ triethylamine to ensure the rhodamine dyes were in the zwitterionic form. The absorbance values at $\lambda_{\max }$ were measured on $5 \mu \mathrm{M}$ samples $(\mathrm{n}=2)$ using a quartz 96-well microplate (Hellma) and a FlexStation3 microplate reader (Molecular Devices). Values of dielectric constant $\left(\varepsilon_{\mathrm{r}}\right)$ were as previously reported ${ }^{36}$. We then calculated $K_{\mathrm{L}-\mathrm{Z}}$ using the following equation ${ }^{29}: K_{\mathrm{L}-\mathrm{Z}}=\left(\varepsilon_{\mathrm{dw}} / \varepsilon_{\mathrm{max}}\right) /\left(1-\varepsilon_{\mathrm{dw}} / \varepsilon_{\mathrm{max}}\right) . \varepsilon_{\mathrm{dw}}$ is the extinction coefficient of the dyes in a $1: 1 \mathrm{v} / \mathrm{v}$ dioxane:water solvent mixture (Fig. 1e); this dioxane-water mixture was chosen to give the maximum spread of $K_{\mathrm{L}-\mathrm{Z}}$ values (Supplementary Fig. 1a). $\varepsilon_{\max }$ is the maximal extinction coefficients measured in different solvent mixtures depending on dye type: $0.1 \% \mathrm{v} / \mathrm{v}$ trifluoroacetic acid (TFA) in 3,3,3-trifluoroethanol (TFE) for the rhodamines (1, 5-12) and carborhodamines $(\mathbf{2}, \mathbf{2 2}) ; 0.1 \% \mathrm{v} / \mathrm{v}$ TFA in ethanol for the Si-rhodamines $(\mathbf{3}, \mathbf{2 6}) ; 0.01 \% \mathrm{v} / \mathrm{v}$ $\mathrm{Et}_{3} \mathrm{~N}$ in TFE for the rhodols $(\mathbf{1 6}, \mathbf{1 7})$.

Quantum yield determination. All reported absolute fluorescence quantum yield values $(\Phi)$ were measured in our laboratory under identical conditions using a Quantaurus-QY spectrometer (model C11374, Hamamatsu). This instrument uses an integrating sphere to determine photons absorbed and emitted by a sample. Measurements were carried out using dilute samples $(A<0.1)$ 
and self-absorption corrections ${ }^{37}$ were performed using the instrument software. Reported values are averages $(\mathrm{n}=3)$. The quantum yield for compound $\mathbf{8}$ at $\mathrm{pH} 5.0$ was taken in $10 \mathrm{mM}$ sodium citrate buffer containing $150 \mathrm{mM} \mathrm{NaCl}$.

Molecular modeling. Computational experiments were performed using Gaussian $09 .{ }^{38}$ DFT and TD-DFT methods were used to calculate the spectral properties of the azetidinyl rhodamine compounds (Table 1). Calculations were performed at the B3LYP/6-31+G(d,p)/IEFPCM and TD-B3LYP/6-31+G(d,p)/IEFPCM theory levels for the ground states and excited states respectively. Frequency calculations confirmed that an energy minimum was found in geometry optimizations. Linear response solvation with the IEFPCM model was sufficient to study the excited state energies. Evaluations of TD-DFT theory have discussed the overestimation of excitation energies $^{39,40}$, and previous studies of rhodamine excited states have reported using $\sim 0.4 \mathrm{eV}$ correction to account for this overestimation ${ }^{41,42}$. We used a consistent $-0.4 \mathrm{eV}$ correction was applied to the calculated excited state energies, which gave good agreement with spectroscopy experiments (Fig. 1d).

Measurement of increase in absorbance of HaloTag ligands 4, 23, 24, 27, and 28 upon attachment with HaloTag protein. HaloTag protein used as a $100 \mu \mathrm{M}$ solution in $75 \mathrm{mM} \mathrm{NaCl}$, $50 \mathrm{mM}$ TRIS $\cdot \mathrm{HCl}$, pH 7.4 with 50\% v/v glycerol (TBS-glycerol). Absorbance measurements were performed in $1 \mathrm{~mL}$ quartz cuvettes. HaloTag ligands $4, \mathbf{2 3}, \mathbf{2 4}, \mathbf{2 7}$, and $28(5 \mu \mathrm{M})$ were dissolved in $10 \mathrm{mM}$ HEPES, pH 7.3 containing $0.1 \mathrm{mg} \cdot \mathrm{mL}^{-1} \mathrm{CHAPS}$. An aliquot of HaloTag protein (1.5 equiv) or an equivalent volume of TBS-glycerol blank was added and the resulting mixture was incubated until consistent absorbance signal was observed ( $\sim 60 \mathrm{~min})$. Absorbance scans are averages $(n=2)$. 
Multiphoton spectroscopy. HaloTag ligands 4, 14, 15, 18, 24, and $27(5 \mu \mathrm{M})$ were incubated with excess purified HaloTag protein (1.5 equiv) in 10 mM HEPES, pH 7.3 containing 0.1 $\mathrm{mg} \cdot \mathrm{mL}^{-1} \mathrm{CHAPS}$ as above and incubated for $24 \mathrm{~h}$ at $4{ }^{\circ} \mathrm{C}$. These solutions were then diluted to 1 $\mu \mathrm{M}$ in $10 \mathrm{mM}$ HEPES buffer, $\mathrm{pH} 7.3$ and the two-photon excitation spectra were measured as previously described ${ }^{43,44}$. Briefly, measurements were taken on an inverted microscope (IX81, Olympus) equipped with a $60 \times, 1.2 \mathrm{NA}$ water objective (Olympus). Dye-protein samples were excited with pulses from an $80 \mathrm{MHz}$ Ti-Sapphire laser (Chameleon Ultra II, Coherent) for 710$1080 \mathrm{~nm}$ and with an OPO (Chameleon Compact OPO, Coherent) for 1000-1300 nm. Fluorescence collected by the objective was passed through a dichroic filter (675DCSXR, Omega) and a short pass filter (720SP, Semrock) and detected by a fiber-coupled Avalanche Photodiode (SPCM_AQRH-14, Perkin Elmer). For reference, a two-photon excitation spectrum was also obtained for the red fluorescent protein mCherry $(1 \mu \mathrm{M})$, in the same HEPES buffer. All excitation spectra are corrected for the wavelength-dependent transmission of the dichroic and band-pass filters, and quantum efficiency of the detector.

General cell culture and fluorescence microscopy. COS7 cells (ATCC) were cultured in Dulbecco's modified Eagle medium (DMEM, phenol red-free; Life Technologies) supplemented with 10\% (v/v) fetal bovine serum (Life Technologies), $1 \mathrm{mM}$ GlutaMAX (Life Technologies) and maintained at $37{ }^{\circ} \mathrm{C}$ in a humidified $5 \%(\mathrm{v} / \mathrm{v}) \mathrm{CO}_{2}$ environment. The cells have integrated a histone $\mathrm{H} 2 \mathrm{~B}-\mathrm{HaloTag}$ expressing plasmid via the piggyback transposase, under the selection of $500 \mu \mathrm{g} / \mathrm{ml}$ Geneticin (Life Technologies). This 'H2B-Halo' cell line undergoes regular mycoplasma testing by the Janelia Cell Culture Facility. Cells were imaged on a confocal microscope in the Janelia Imaging Facility (Zeiss 710, W Plan APO 20×/1.8 D) using the indicated filter sets. 
Comparison of $\mathbf{J F}_{\mathbf{5 4 9}}$ and $\mathbf{J F}_{\mathbf{5 2 5}}$. For the dye loading comparison (Fig $\mathbf{1 h}$ ), H2B-Halo cells were stained for varying amounts of time with $100 \mathrm{nM}$ of either $\mathrm{JF}_{525}-$ HaloTag ligand 14 or $\mathrm{JF}_{549}-$ HaloTag ligand 15. The dye was washed from the cells and subsequently labeled with $\mathrm{JF}_{646}-$ HaloTag ligand 4 at $1 \mu \mathrm{M}$ for $30 \mathrm{~min}$. Fluorescence of $\mathrm{JF}_{646}-$ HaloTag ligand was quantified from the nuclear signals in summed confocal image stacks collected with $633 \mathrm{~nm} \mathrm{Ex/638-759} \mathrm{nm} \mathrm{Em}$ and analysed using Fiji. ${ }^{45}$ The integrated density of the nuclear signal was corrected by subtracting the integrated density of adjacent background regions. Labeling is expressed as the percent of the $\mathrm{JF}_{646}-$ HaloTag fluorescence displaced by the $\mathrm{JF}_{525}-$ and $\mathrm{JF}_{549}-$ HaloTag ligands. The nuclear staining of these cells by the $\mathrm{JF}_{525}-$ HaloTag ligand (Fig. 1g) is displayed as a maximum intensity projection of confocal image stacks, $514 \mathrm{~nm} \mathrm{Ex/530-657} \mathrm{Em.}$

Comparison of $\mathbf{J F}_{\mathbf{5 0 3}}$ and other $\mathbf{4 8 8} \mathbf{n m}$-excited dyes. H2B-Halo COS7 cells were labeled with $200 \mathrm{nM}$ of HaloTag ${ }^{\circledR}$ R110Direct ${ }^{\mathrm{TM}}$ ligand (19, Promega), HaloTag ligand $\mathbf{2 0}^{26}$, or $\mathrm{JF}_{503}-$ HaloTag ligand 18 over a time course of $0-2$ h. Cells were washed $2 \times$ with PBS and fixed with 4\% w/v paraformaldehyde in $0.1 \mathrm{M}$ phosphate for $30 \mathrm{~min}$, followed by two more washes with PBS. Cells were imaged using confocal microscopy with $488 \mathrm{~nm}$ Ex/515-565 nm Em. The nuclear staining of these cells by the $\mathrm{JF}_{525}-$ HaloTag ligand (Fig. 2c) is displayed as a maximum intensity projection of confocal image stacks. Corrected nuclear fluorescence was calculated as above to determine the cell loading profile (Supplementary Fig. 1c). To test the relative bleaching rates of these three dyes under imaging conditions (Fig. 2d), cells were stained and fixed as previously described for $2 \mathrm{~h}$ and then bleached with $488 \mathrm{~nm}$ at twice the typical power and imaged after each of 70 cycles. Bleached fluorescence data are normalized to the initial fluorescence levels. 
Comparison of HaloTag ligands 4, 23, 24, 27, and 28 in cells. H2B-Halo COS7 cells were labeled with $250 \mathrm{nM}$ of $\mathrm{JF}_{608}-$ HaloTag ligand (23), $\mathrm{JF}_{585}-$ HaloTag ligand (24), $\mathrm{JF}_{646}-$ HaloTag ligand (4), $\mathrm{JF}_{635}-$ HaloTag ligand (27), or SiTMR-HaloTag ligand (28; Supplementary Fig. 1d) and imaged by confocal microscopy using $594 \mathrm{~nm} \mathrm{Ex/599-734} \mathrm{nm} \mathrm{Em}\left(\mathrm{JF}_{608}\right.$ and $\left.\mathrm{JF}_{585}\right)$ or 633 $\mathrm{nm} \mathrm{Ex/638-759} \mathrm{nm} \mathrm{Em} \mathrm{(} \mathrm{JF}_{646} \mathrm{JF}_{635}$, or SiTMR). All five samples were imaged via confocal microscopy without washing out the dyes. Signal to noise ratios were determined using the mean fluorescence of the nuclei relative to a region adjacent to each nuclei using Fiji ${ }^{45}$ ( $\mathrm{n}=152-275$ areas as noted; Fig. 3g-j, Supplementary Fig. 1f).

Staining with SNAP-tag ligands. COS7 cells were transfected with pSNAP-H2B (New England Biolabs) and stable integration of this plasmid was selected for using $600 \mu \mathrm{g} / \mathrm{ml} \mathrm{Geneticin}{ }^{\circledR}$ (Life Technologies). This cell line expresses the histone H2B protein fused to the $26 \mathrm{~m}$ version of the SNAP protein. Cells were stained with four different dyes as follows; $\mathrm{JF}_{503}-\mathrm{cpSNAP-tag}$ ligand (29, $2 \mu \mathrm{M}$ for $90 \mathrm{~min}), \mathrm{JF}_{525}-\mathrm{SNAP}$-tag ligand (30, $3 \mu \mathrm{M}$ for $\left.30 \mathrm{~min}\right), \mathrm{JF}_{585}-\mathrm{SNAP}$-tag ligand (31, $2 \mu \mathrm{M}$ for $3 \mathrm{hr}$ with $0.2 \% \mathrm{w} / \mathrm{v}$ Pluronic F-127), $\mathrm{JF}_{635}-\mathrm{SNAP}-\operatorname{tag}$ ligand (32, $2 \mu \mathrm{M}$ for $2 \mathrm{~h}$ with $0.2 \% \mathrm{w} / \mathrm{v}$ Pluronic F-127). After staining, cells were washed three times with complete media, followed by a 20 -min incubation in a $37^{\circ} \mathrm{C}, 5 \% \mathrm{CO}_{2}$, humidified incubator. The media was replaced again immediately prior to imaging.

Staining of Drosophila larvae. The central nervous system of a third instar Drosophila melanogaster was dissected in physiological saline. This larva expressed myristoylated HaloTag in the 'Basin' neurons under control of the enhancer fragment R72F11. ${ }^{46}$ The isolated nervous system was incubated in physiological saline containing $1 \mu \mathrm{M} \mathrm{JF}_{635}-$ HaloTag ligand (27) for 10 min at room temperature. The specimen was then embedded in agarose and imaged with the SiMView light-sheet microscope. ${ }^{31}$ 
General information for mouse in vivo experiments. Male mice, 3-8 months old, were used for viral infection, dye injection, and in vivo imaging of neurons in the visual cortex (V1): The Scnn1a-Tg3-Cre (Jax no. 009613) line was used for imaging in L4; and Rbp4-Cre mice (MMRRC no. 031125-UCD) were used for imaging in L5 neurons. All experimental protocols were conducted according to the National Institutes of Health guidelines for animal research and were approved by the Institutional Animal Care and Use Committee at the Janelia Research Campus, HHMI.

Cranial window implant and virus injection. A craniotomy was carried out at the same time as the virus injection to provide optical access for in vivo imaging experiments. Mice were anesthetized with isoflurane $\left(1-2 \% \mathrm{v} / \mathrm{v}\right.$ in $\left.\mathrm{O}_{2}\right)$ and given the analgesic buprenorphine $(\mathrm{SC}, 0.3$ $\mathrm{mg} / \mathrm{kg}$ ). Using aseptic technique, a $3.5 \mathrm{~mm}$-diameter craniotomy was made over the left V1 region of the brain of anaesthetized mouse (center: $3.4 \mathrm{~mm}$ posterior to Bregma; $2.7 \mathrm{~mm}$ lateral from midline). The dura was left intact. HaloTag and GCaMP6s was cotranduced using the viral vector: AAV2/1.synapsin.FLEX.GCaMP6s.P2A.HaloTag. WPRE $\left(\sim 5 \times 10^{12}\right.$ infectious units per $\mathrm{ml}, 30 \mathrm{nl}$ per site). The virus was injected using a glass pipette beveled at $45^{\circ}$ with a $15-20-\mu \mathrm{m}$ opening and back-filled with mineral oil. A fitted plunger controlled by a hydraulic manipulator (Narashige, MO10) was inserted into the pipette and used to load and inject the solution into 6 sites of left V1 (3.4-4.4 mm posterior to Bregma; 2.2-2.8 mm lateral from midline; $\sim 0.5 \mathrm{~mm}$ distance between each injection site, $0.5 \mathrm{~mm}$ below pia). A cranial window made of a single glass coverslip (Fisher Scientific no. 1.5) was embedded in the craniotomy and sealed in place with dental acrylic. A titanium head-post was attached to the skull with cyanoacrylate glue and dental acrylic. 
Dye Administration. $\mathrm{JF}_{585}-$ HaloTag ligand (24) was administered to mice 3-4 weeks after the cranial window installation and viral injection. Dye solution was prepared by first dissolving 100 nmol (76 $\mu \mathrm{g})$ of $\mathrm{JF}_{585}-$ HaloTag ligand (24) in $20 \mu \mathrm{L}$ DMSO. After vortexing, $20 \mu \mathrm{L}$ of a Pluronic F-127 solution (20\% w/w in DMSO) was added and this stock solution was diluted into $100 \mu \mathrm{L}$ or $200 \mu \mathrm{L}$ sterile saline for IV (tail vein) or IP injection, respectively.

In vivo wide-field imaging and analysis. Mice were head-fixed and awake during the imaging period and were therefor habituated to experimental handling and head fixation starting 1-week post-surgery. During each habituation session, mice were head-fixed onto the sample stage with body restrained under a half-cylindrical cover. The habituation procedure was repeated 3-4 times for each animal for a duration of 15-60 minutes. For in vivo wide-field imaging, an external fluorescence light source (Leica EL6000, Leica) was used for excitation of GCaMP6s (green channel) and $\mathrm{JF}_{585}-$ HaloTag ligand (red channel). Images were acquired via Leica Application Suite 4.5 (Leica). Wide-field images in green (1 second exposure) and red (4 second exposure) channels were acquired at multiple time intervals over two weeks under the same imaging conditions and the images were aligned with the Stackreg plugin in ImageJ. The mean values in the same area of red and green channels were plotted to track the labeling kinetics and turnover of $\mathrm{JF}_{585}-$ HaloTag in vivo.

In vivo two-photon imaging and analysis For in vivo two-photon imaging, GCaMP6s and $\mathrm{JF}_{585}-$ HaloTag were excited at $940 \mathrm{~nm}$ and $1100 \mathrm{~nm}$, respectively, using a femtosecond laser source (InSight DeepSee, Spectra-Physics), and imaged using an Olympus 25× 1.05 NA objective and a homebuilt two-photon microscope ${ }^{47}$. Images were acquired from 200 to $550 \mu \mathrm{m}$ below the pia with post-objective power ranging between 20 and $60 \mathrm{~mW}$. No photobleaching or photodamage of tissue was observed. Typical imaging settings were composed of $256 \times 256$ 
pixels, with $1.2 \mu \mathrm{m}$ per pixel, and a $\sim 3 \mathrm{~Hz}$ frame rate. The time-lapse calcium images of spontaneous neuronal activity in awake, head fixed mice were recorded and analyzed with custom programs written in MATLAB (Mathworks). Lateral motion present in head-fixed awake mice was corrected using a cross-correlation-based registration algorithm ${ }^{48}$, where crosscorrelation was calculated to determine frame shift in $\mathrm{x}$ and $\mathrm{y}$ directions. Cortical neurons were outlined by hand as regions of interest (ROIs). The fluorescence time course of each ROI was used to calculate its calcium transient as $\Delta \mathrm{F} / \mathrm{F}(\%)=\left(\mathrm{F}-\mathrm{F}_{0}\right) / \mathrm{F}_{0} \times 100$, with the baseline fluorescence $\mathrm{F}_{0}$ being the mode of the fluorescence intensity histogram of this ROI. 
a

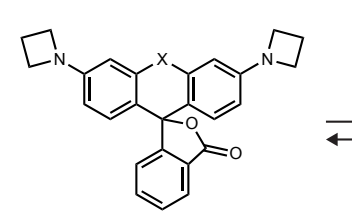

lactone (L)

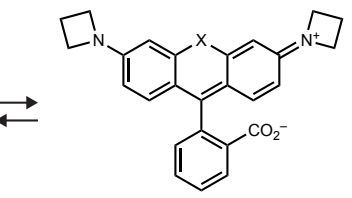

zwitterion $(\mathrm{Z})$

\begin{tabular}{cccccc}
\hline Dye & $\mathrm{X}$ & $\lambda_{\max }(\mathrm{nm})$ & $\varepsilon\left(\mathrm{M}^{-1} \mathrm{~cm}^{-1}\right)$ & $\lambda_{\mathrm{em}}(\mathrm{nm})$ & $\Phi$ \\
\hline $\mathbf{1}$ & $\mathrm{O}$ & 549 & 101,000 & 571 & 0.88 \\
$\mathbf{2}$ & $\mathrm{C}\left(\mathrm{CH}_{3}\right)_{2}$ & 608 & 99,000 & 631 & 0.67 \\
& & & & & \\
\hline
\end{tabular}

b
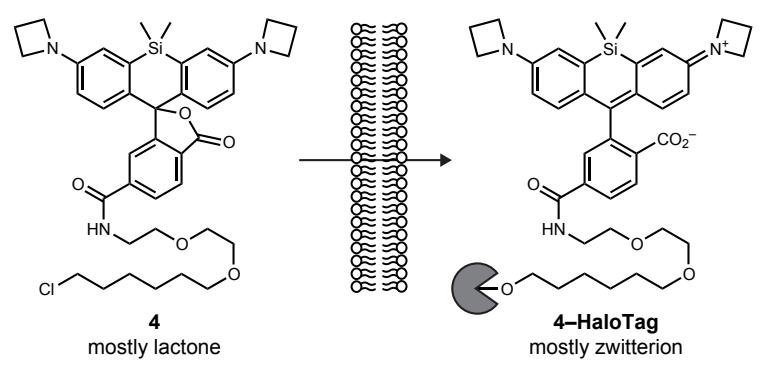
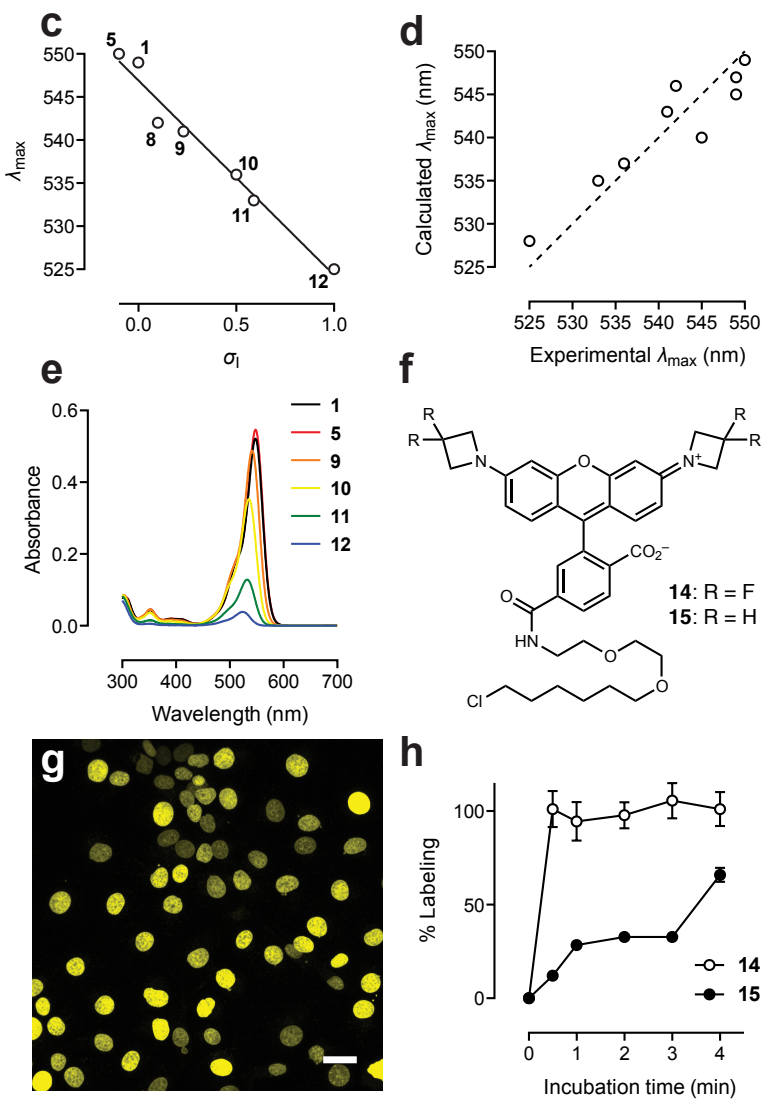

Figure 1. Fine-tuning rhodamine dyes using 3-substituted azetidines. (a) Properties of azetidinyl rhodamines 1-3. All properties are taken in $10 \mathrm{mM}$ HEPES, pH 7.3. (b) Structure of $\mathrm{JF}_{646}-$ HaloTag ligand and schematic illustrating high cell permeability and fluorogenic labeling reaction. (c) Correlation of experimental $\lambda_{\max } v s$. inductive Hammett constants $\left(\sigma_{l}\right)$ for dyes 1, 5, 8-12. For the geminal disubstituted compounds 5 and 12 the $\sigma_{1}$ of the substituent was doubled. Solid line shows linear regression $\left(R^{2}=0.97\right)$. (d) Correlation between calculated and experimental $\lambda_{\max }$ values for dyes 1, 5-12; dashed line shows ideal fit. (e) Absolute absorbance of 1, 5, 9-12 (5 $\mu \mathrm{M})$ in 1:1 dioxane: $\mathrm{H}_{2} \mathrm{O}$. (f) Chemical structure of $\mathrm{JF}_{525}$ HaloTag ligand 14 and $\mathrm{JF}_{549}-$ HaloTag ligand 15. (g) Image of live, washed COS7 cells expressing histone H2B-HaloTag fusions and labeled with ligand 14. Scale bar: $30 \mu \mathrm{m}$. (h) Plot of percent labeling of histone H2B-HaloTag fusions in live cells vs. incubation time for ligands 14 and 15 determined by chasing with ligand 4 . 
Table 1. Synthesis and properties of azetidinyl rhodamines 1, 5-12.

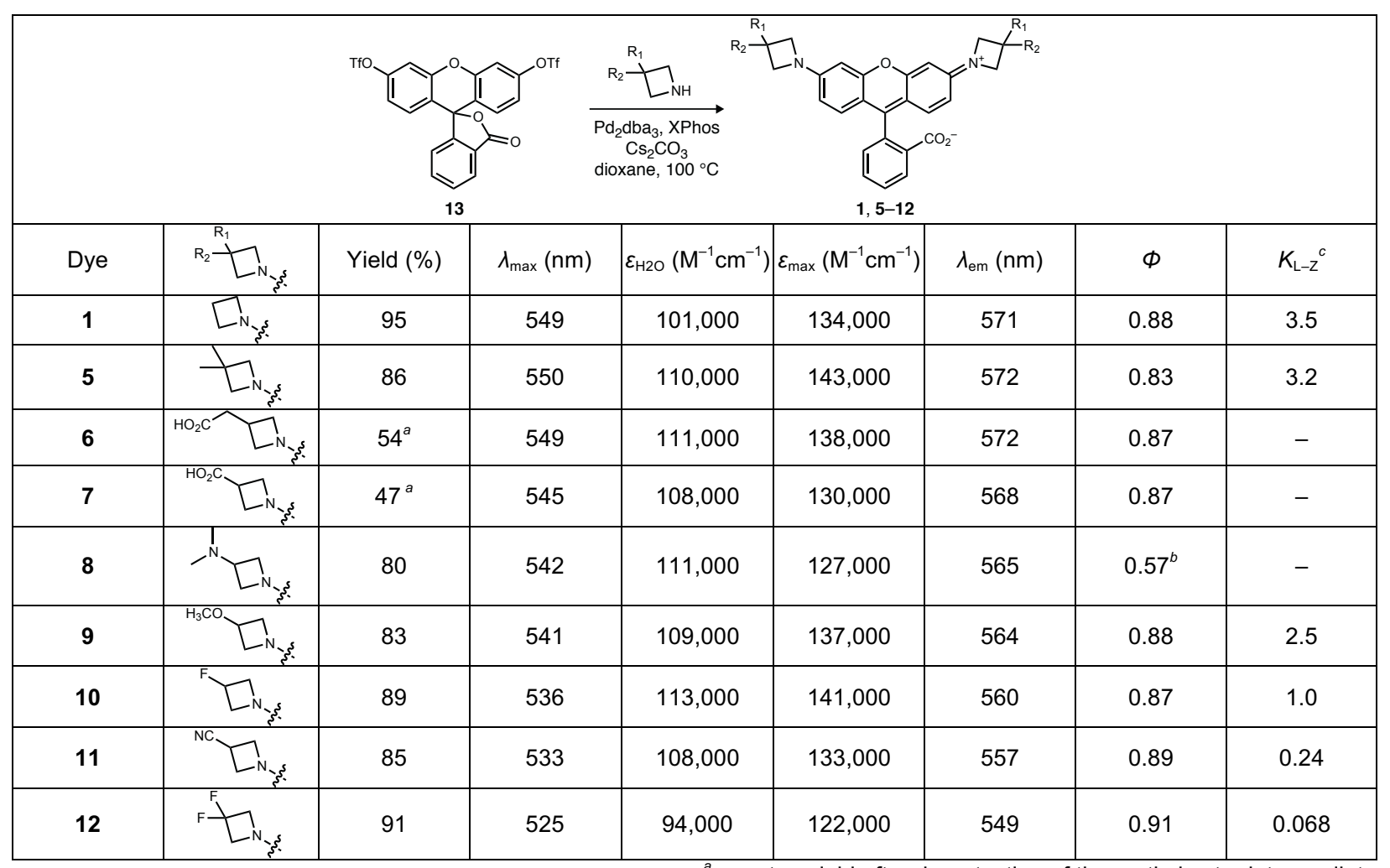

${ }^{a}$ two-step yield after deprotection of the methyl ester intermediate ${ }^{c}$ equilibrium measured in 1:1 $\mathrm{v} / \mathrm{v}$ dioxane:water 
a
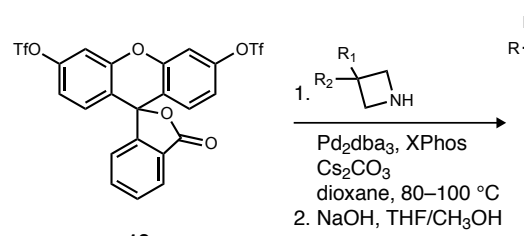

13

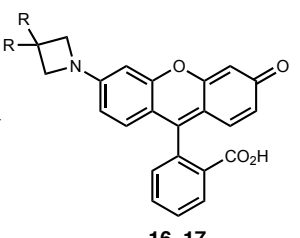

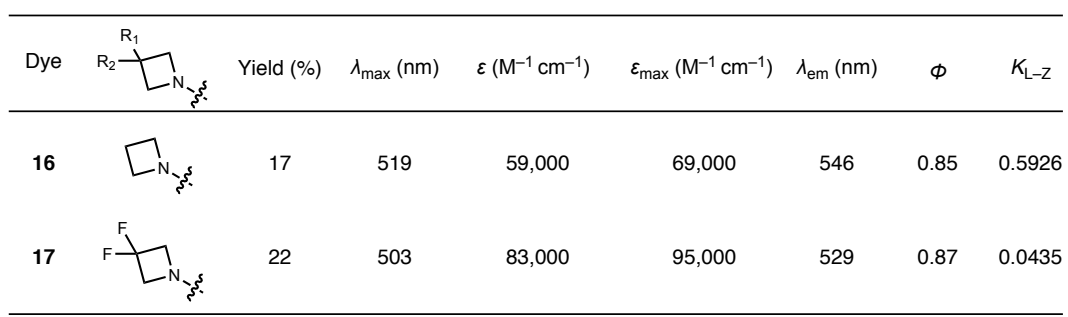
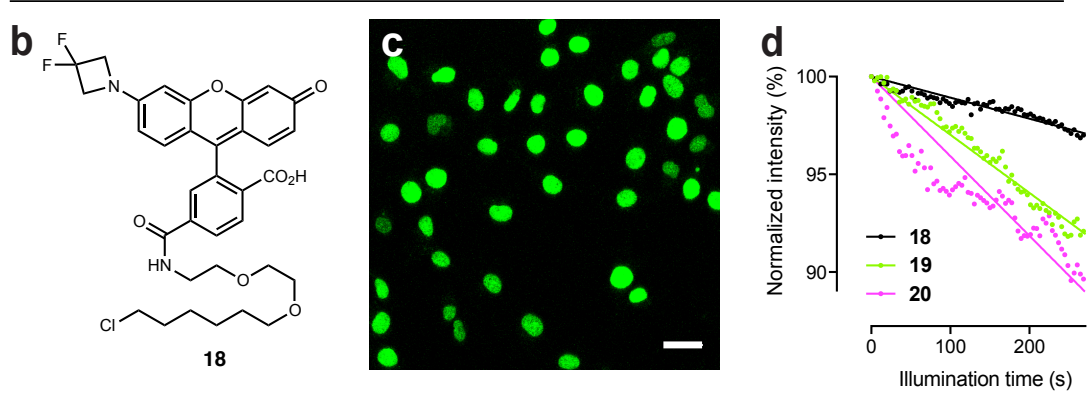

Figure 2. Design and synthesis of $\mathbf{J F}_{503}$ (a) Synthesis and properties of azetidinyl-rhodols 16-17. Yields are for two steps; $K_{\mathrm{L}-\mathrm{Z}}$ values were determined in 1:1 dioxane: $\mathrm{H}_{2} \mathrm{O}(\mathbf{b})$ Structure of $\mathrm{JF}_{503}-$ HaloTag ligand 18. (c) Image of live, washed COS7 cells expressing histone H2B-HaloTag fusions and labeled with ligand 18. Scale bar: $35 \mu \mathrm{m}$. (d) Comparison of the photostability of cells labeled with $\mathbf{1 8}$ and cells labeled with $488 \mathrm{~nm}$-excited dyes 19 and 20 (Supplementary Fig. 1b); the initial photobleaching measurements are fitted to a linear regression. 
a

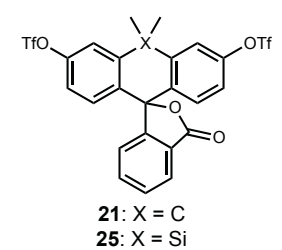

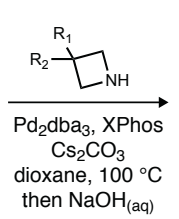

then $\mathrm{NaOH}_{(\mathrm{aq})}$

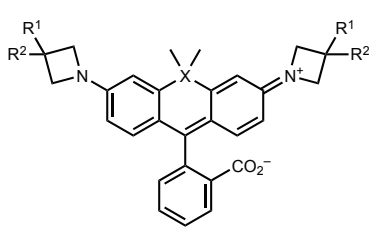

$2,3,22$, and 26

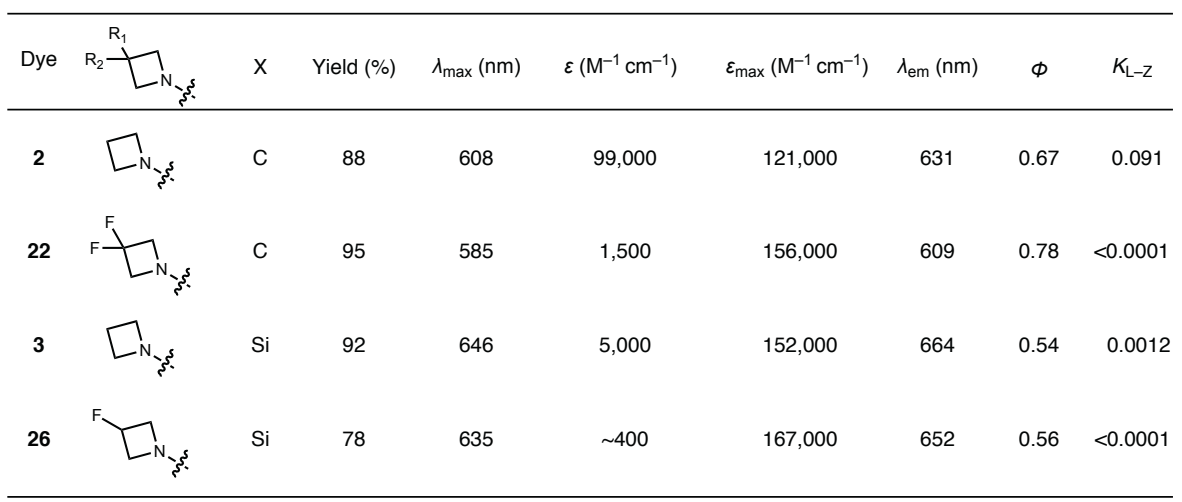
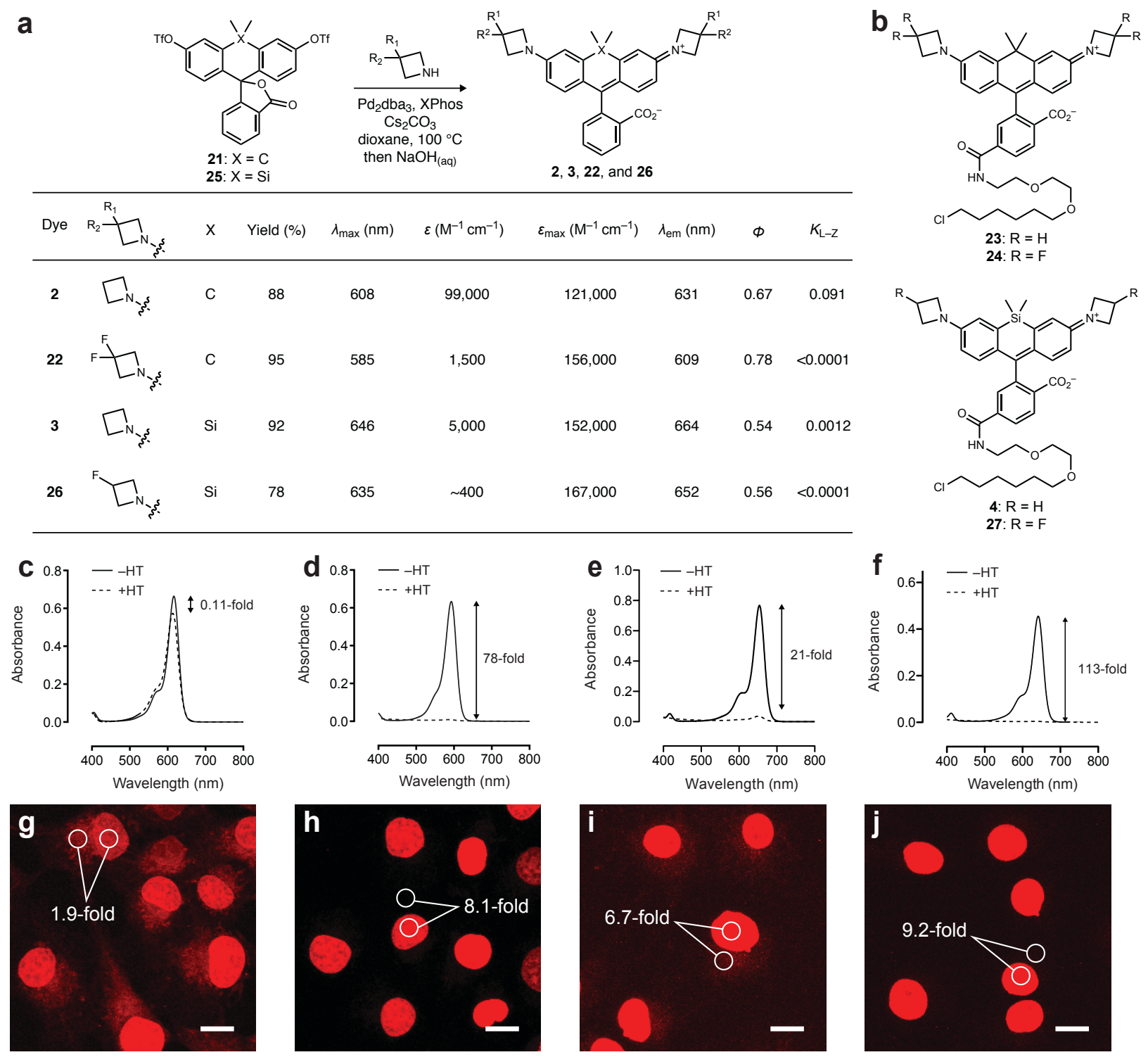

Figure 3. Design and synthesis of $\mathbf{J F}_{585}$ and $\mathbf{J F}_{635}$ (a) Synthesis and properties of azetidinylcarborhodamines 2, 22 and azetidinyl Si-rhodamines 3, 26. $K_{\mathrm{L}-\mathrm{Z}}$ values were determined in 1:1 dioxane: $\mathrm{H}_{2} \mathrm{O}$ (b) Structure of HaloTag ligands derived from $\mathrm{JF}_{608}(\mathbf{2 3}), \mathrm{JF}_{585}(\mathbf{2 4}), \mathrm{JF}_{646}$ (4), and $\mathrm{JF}_{635}(\mathbf{2 7})$. (c-f) Absorbance of HaloTag ligands in the absence $(-\mathrm{HT})$ or presence $(+\mathrm{HT})$ of excess HaloTag protein. (c) $\mathrm{JF}_{608}$ ligand 23. (d) $\mathrm{JF}_{585}$ ligand 24. (e) $\mathrm{JF}_{646}$ ligand 4. (f) $\mathrm{JF}_{635}$ ligand 24. (g-j) Images of COS7 cells expressing HaloTag-histone H2B fusion and labeled with $250 \mathrm{nM}$ of HaloTag ligands for $1 \mathrm{~h}$ and imaged directly without washing. The image for each dye pair was taken with identical microscope settings: $\lambda_{\mathrm{ex}}=$ $594 \mathrm{~nm}$ for $\mathbf{g}$ and $\mathbf{h} ; \lambda_{\mathrm{ex}}=647 \mathrm{~nm}$ for $\mathbf{i}$ and $\mathbf{j}$. Numbers indicate mean signal (nuclear) to background (cytosol; SNB) in three fields of view. (g) $\mathrm{JF}_{608}$ ligand 23 (SNB from $\mathrm{n}=224$ areas). (h) $\mathrm{JF}_{585}$ ligand 24 (SNB from $n=235$ areas). (i) $\mathrm{JF}_{646}$ ligand 4 (SNB from $n=175$ areas). (j) $\mathrm{JF}_{635}$ ligand 27 (SNB from $n=$ 278 areas). Scale bars: $15 \mu \mathrm{m}$. 

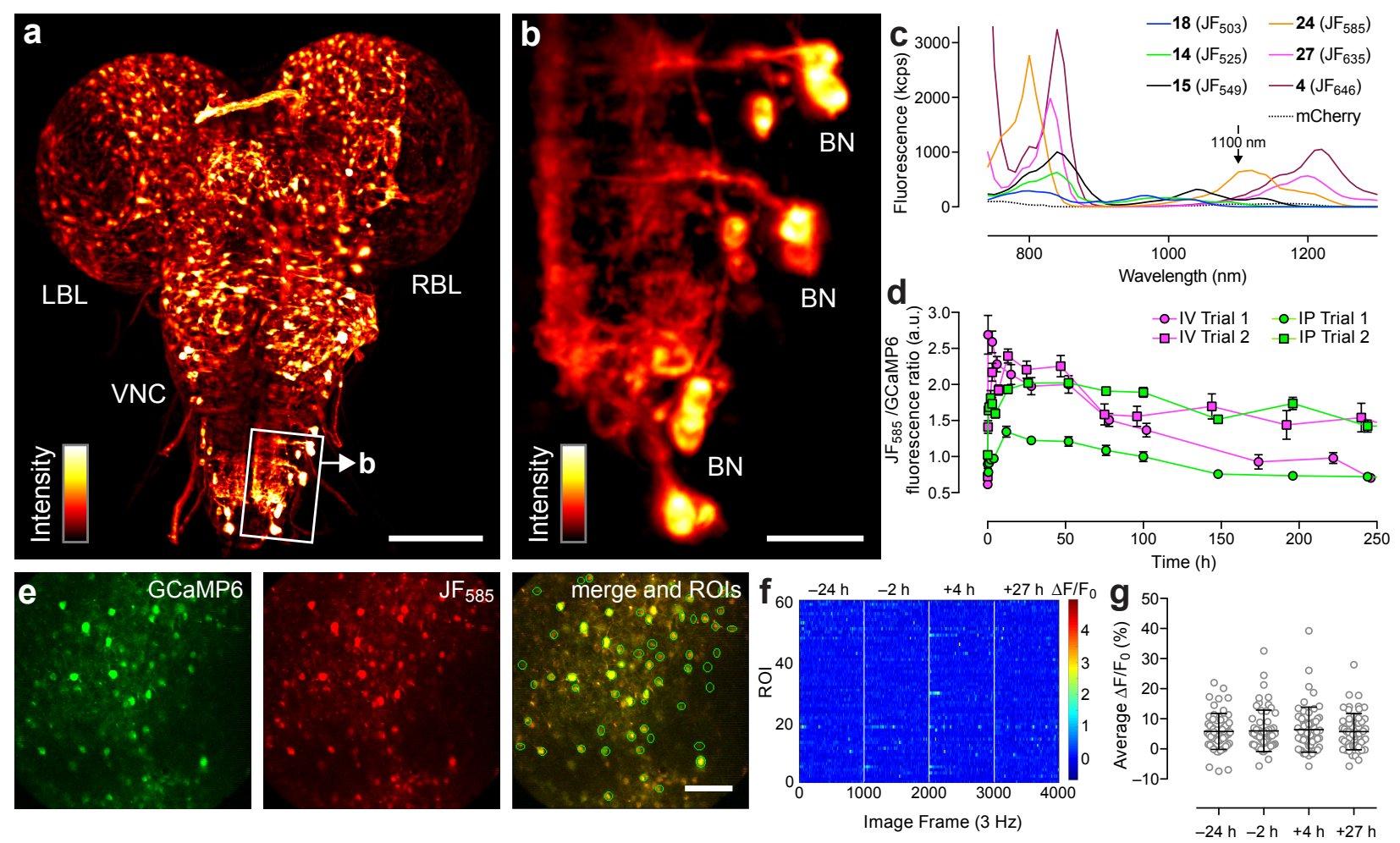

Figure 4. Labeling in tissue and in vivo. (a) SiMView light-sheet microscopy image of the central nervous system of a third instar Drosophila larva expressing myristoylated HaloTag protein in 'Basin' neurons (BNs) and stained with $\mathrm{JF}_{635}-\mathrm{HaloTag}$ ligand (27); LBL: left brain lobe; VNC: ventral nerve cord; RBL: right brain lobe. Scale bar: $100 \mu \mathrm{m}$. (b) Zoom in of boxed area in panel a showing individual BN cell bodies. Scale bar: $20 \mu \mathrm{m}$. (c) Two-photon fluorescence excitation spectra of HaloTag conjugates $(1 \mu \mathrm{M})$ from HaloTag ligands 4, 14, 15, 18, 24, and 27 in $10 \mathrm{mM}$ HEPES buffer (pH 7.3). The two-photon excitation spectra for $\mathrm{mCherry}$ is shown for reference. (d) Ratio of $\mathrm{JF}_{585}$ fluorescence to GCaMP6 epifluorescence at different time points after a single injection of $\mathrm{JF}_{585}-$ HaloTag ligand $(\mathbf{2 4}, 100 \mathrm{nmol})$ either intravenous (IV) or intraperitoneal (IP); $\mathrm{n}=2$; error bars show \pm s.e.m. (e) Two-photon microscopy images of neurons in layer 5 of the visual cortex coexpressing GCaMP6s (green) and $\mathrm{JF}_{585}$-labeled HaloTag (red) after IV injection of ligand $24(t=5 \mathrm{~h})$. Scale bar: $100 \mu \mathrm{m}$. Green circles in the merged image indicate individual neurons as regions of interest (ROls). (f) Raster plot of spontaneous neuronal activity in different ROIs $\left(n=61\right.$ ) before and after labeling with $\mathrm{JF}_{585}-$ HaloTag ligand $(\mathbf{2 4})$. (g) Plot of average spontaneous neural activity in each $\mathrm{ROI}$ before and after labeling with $\mathrm{JF}_{585}$-HaloTag ligand (24); error bars show \pm s.d.; no significant difference is observed between time points (one-way ANOVA: $p=$ 0.95). 


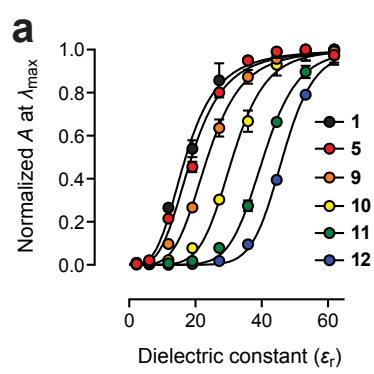

b
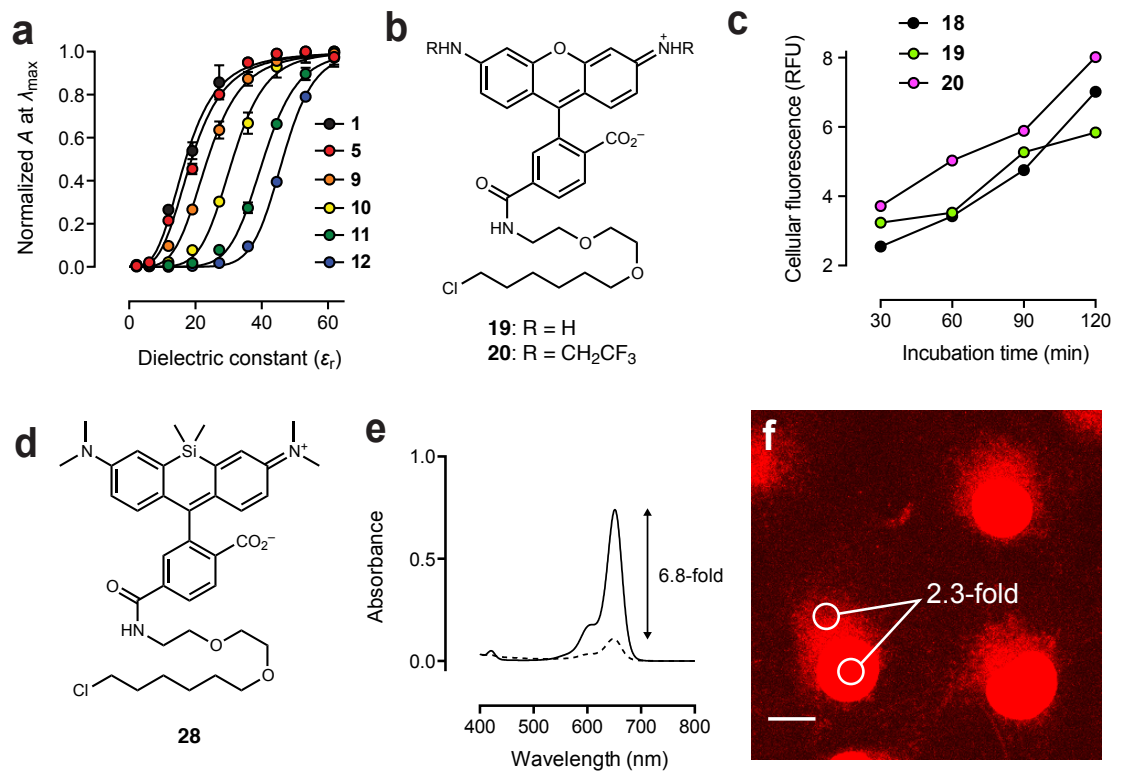

Supplementary Figure 1. (a) Normalized absorption vs. dielectric constant $\left(\varepsilon_{r}\right)$ for dyes 1, 5, and 9-12. (b) Chemical structures of known HaloTag ligands 19 and 20. (c) Plot of average cellular fluorescence vs. incubation time for live cells loaded with ligands 18-20. (d) Chemical structure of SiTMR-HaloTag ligand 28. (e) Absorbance of SiTMR-HaloTag ligand 28 in the absence $(-\mathrm{HT})$ or presence $(+\mathrm{HT})$ of excess HaloTag protein. (f) Images of COS7 cells expressing HaloTag-histone H2B fusion and labeled with 250 $\mathrm{nM}$ of HaloTag ligand 28 for $1 \mathrm{~h}$ and imaged directly without washing. The number indicates mean signal (nuclear) to background (cytosol; SNB) in three fields of view ( $n=152$ areas). This image was taken with identical microscope settings to those used with ligands 4 and 27 (Fig. 3i-j). Scale bar: $15 \mu \mathrm{m}$. 

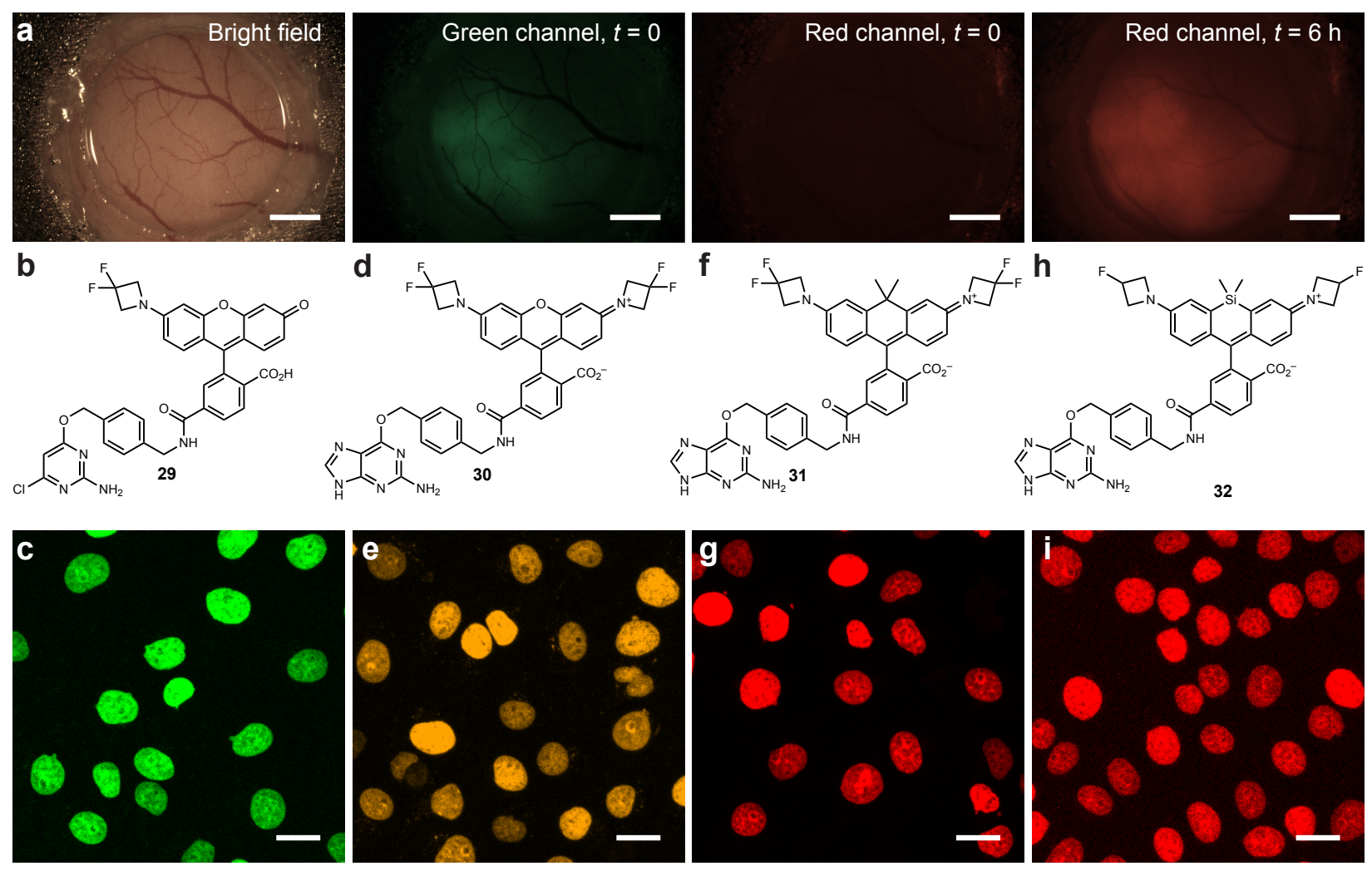

Supplementary Figure 2. (a) Representative images from the labeling time course for $\mathrm{JF}_{585}-\mathrm{HaloTag}$ ligand (24) in vivo. Bright field image showing cranial window and epi-fluorescence images of green (GCaMP6; $t=0$ ) and red $\left(\mathrm{JF}_{585}, t=0\right.$ and $6 \mathrm{~h}$ ). (b,c) Structure of $\mathrm{JF}_{503}-\mathrm{cpSNAP}$-tag ligand (29) and image of live COS7 cells expressing SNAP-tag-histone H2B and stained with ligand 29. (d,e) Structure of $\mathrm{JF}_{525}$ SNAP-tag ligand (30) and image of live COS7 cells expressing SNAP-tag-histone H2B and stained with ligand 30. $(\mathbf{f}, \mathbf{g})$ Structure of $\mathrm{JF}_{585}-\mathrm{SNAP}$-tag ligand $(\mathbf{3 1})$ and image of live COS7 cells expressing SNAP-tag-histone H2B and stained with ligand 31. (h,i) Structure of $\mathrm{JF}_{635}-\mathrm{SNAP}$-tag ligand (32) and image of live COS7 cells expressing SNAP-tag-histone H2B and stained with ligand 32. Scale bars for images in $\mathbf{c}, \mathbf{e}, \mathbf{g}$, and $\mathbf{i}: 15 \mu \mathrm{m}$.

Supplementary Video 1. Layer 5 neurons expressing GCaMP6s and HaloTag were labeled with $\mathrm{JF}_{585}-$ HaloTag ligand (24) through intraperitoneal (IP) injection and imaged with two-photon fluorescence microscopy. $\mathrm{JF}_{585}$ was excited at $1100 \mathrm{~nm}$ and the stack $(307 \mu \mathrm{m} \times 307 \mu \mathrm{m} \times 530 \mu \mathrm{m})$ was acquired from 50 to $580 \mu \mathrm{m}$ below dura mater at $2 \mu \mathrm{m}$ step in Z. 3D movie was made by the ImageJ 3D view plugin (unit is in $\mu \mathrm{m})$. 


\section{REFERENCES}

$1 \quad$ Lavis, L.D. \& Raines, R.T. Bright ideas for chemical biology. ACS Chem. Biol. 3, 142155 (2008).

2 Lavis, L.D. \& Raines, R.T. Bright building blocks for chemical biology. ACS Chem. Biol. 9, 855-866 (2014).

3 Xue, L., Karpenko, I.A., Hiblot, J. \& Johnsson, K. Imaging and manipulating proteins in live cells through covalent labeling. Nat. Chem. Biol. 11, 917-923 (2015).

4 Liu, Z., Lavis, L.D. \& Betzig, E. Imaging live-cell dynamics and structure at the singlemolecule level. Mol. Cell 58, 644-659 (2015).

5 Ceresole, M. Verfahren zur Darstellung von Farbstoffen aus der Gruppe des Metaamidophenolphtaleïns. Germany patent 44002 (1887).

6 Beija, M., Afonso, C.A.M. \& Martinho, J.M.G. Synthesis and applications of rhodamine derivatives as fluorescent probes. Chem. Soc. Rev. 38, 2410-2433 (2009).

7 Panchuk-Voloshina, N. et al. Alexa Dyes, a series of new fluorescent dyes that yield exceptionally bright, photostable conjugates. J. Histochem. Cytochem. 47, 1179-1188 (1999).

8 Arden-Jacob, J., Frantzeskos, J., Kemnitzer, N.U., Zilles, A. \& Drexhage, K.H. New fluorescent markers for the red region. Spectrochim. Acta, Part A 57, 2271-2283 (2001).

9 Liu, J.X. et al. Rational design and synthesis of a novel class of highly fluorescent rhodamine dyes that have strong absorption at long wavelengths. Tetrahedron Lett. 44, 4355-4359 (2003).

10 Koide, Y., Urano, Y., Hanaoka, K., Terai, T. \& Nagano, T. Evolution of Group 14 rhodamines as platforms for near-infrared fluorescence probes utilizing photoinduced electron transfer. ACS Chem. Biol. 6, 600-608 (2011).

11 Grimm, J.B. et al. Carbofluoresceins and carborhodamines as scaffolds for high-contrast fluorogenic probes. ACS Chem. Biol. 8, 1303-1310 (2013).

12 Lukinavičius, G. et al. A near-infrared fluorophore for live-cell super-resolution microscopy of cellular proteins. Nature Chem. 5, 132-139 (2013).

13 Grimm, J.B. et al. A general method to improve fluorophores for live-cell and singlemolecule microscopy. Nat. Methods 12, 244-250 (2015).

14 Lavis, L.D., Chao, T.-Y. \& Raines, R.T. Fluorogenic label for biomolecular imaging. ACS Chem. Biol. 1, 252-260 (2006).

15 Watkins, R.W., Lavis, L.D., Kung, V.M., Los, G.V. \& Raines, R.T. Fluorogenic affinity label for the facile, rapid imaging of proteins in live cells. Org. Biomol. Chem. 7, 39693975 (2009).

16 Wysocki, L.M. et al. Facile and general synthesis of photoactivatable xanthene dyes. Angew. Chem., Int. Ed. 50, 11206-11209 (2011).

17 Butkevich, A.N. et al. Fluorescent rhodamines and fluorogenic carbopyronines for superresolution STED microscopy in living cells. Angew. Chem. Int. Ed. 55, 3290-3294 (2016).

18 Grimm, J.B. et al. Synthesis of a far-red photoactivatable Si-rhodamine for super resolution microscopy. Angew. Chem. Int. Ed. 55, 1723-1727 (2016).

19 Grimm, J.B. \& Lavis, L.D. Synthesis of rhodamines from fluoresceins using Pd-catalyzed C-N cross-coupling. Org. Lett. 13, 6354-6357 (2011). 
20 Ticau, S., Friedman, L.J., Ivica, N.A., Gelles, J. \& Bell, S.P. Single-molecule studies of origin licensing reveal mechanisms ensuring bidirectional helicase loading. Cell 161, 513-525 (2015).

21 Liu, Z. et al. 3D imaging of Sox2 enhancer clusters in embryonic stem cells. Elife 3, e04236 (2014).

22 Knight, S.C. et al. Dynamics of CRISPR-Cas9 genome interrogation in living cells. Science 350, 823-826 (2015).

23 Swinstead, E.E. et al. Steroid receptors reprogram FoxA1 occupancy through dynamic chromatin transitions. Cell 165, 593-605 (2016).

24 Bisson-Filho, A.W. et al. Treadmilling by FtsZ filaments drives peptidoglycan synthesis and bacterial cell division. Science 355, 739-743 (2017).

25 Los, G.V. et al. HaloTag: A novel protein labeling technology for cell imaging and protein analysis. ACS Chem. Biol. 3, 373-382 (2008).

26 Mitronova, G.Y. et al. New fluorinated rhodamines for optical microscopy and nanoscopy. Chem. Eur. J. 16, 4477-4488 (2010).

27 Asanuma, D. et al. Acidic - $\mathrm{pH}$ - activatable fluorescence probes for visualizing exocytosis dynamics. Angew. Chem. Int. Ed. 126, 6199-6203 (2014).

28 Hansch, C., Leo, A. \& Taft, R.W. A survey of Hammett substituent constants and resonance and field parameters. Chem. Rev. 91, 165-195 (1991).

29 Hinckley, D.A. \& Seybold, P.G. A spectroscopic/thermodynamic study of the rhodamine B lactone-zwitterion equilibrium. Spectrochim. Acta, Part A 44, 1053-1059 (1988).

30 Whitaker, J.E. et al. Fluorescent rhodol derivatives: Versatile, photostable labels and tracers. Anal. Biochem. 207, 267-279 (1992).

31 Lemon, W.C. et al. Whole-central nervous system functional imaging in larval Drosophila. Nat. Commun. 6, 7924 (2015).

32 Chen, T.W. et al. Ultrasensitive fluorescent proteins for imaging neuronal activity. Nature 499, 295-300 (2013).

33 Bruchez, M.P. Dark dyes-bright complexes: Fluorogenic protein labeling. Curr. Opin. Chem. Biol. 27, 18-23 (2015).

34 Altman, R.B. et al. Cyanine fluorophore derivatives with enhanced photostability. Nat. Methods 9, 68-71 (2012).

35 Palonpon, A.F., Sodeoka, M. \& Fujita, K. Molecular imaging of live cells by Raman microscopy. Curr. Op. Chem. Biol. 17, 708-715 (2013).

36 Critchfield, F.E., Gibson Jr, J.A. \& Hall, J.L. Dielectric constant for the dioxane-water system from 20 to $35^{\circ}$. J. Am. Chem. Soc. 75, 1991-1992 (1953).

37 Suzuki, K. et al. Reevaluation of absolute luminescence quantum yields of standard solutions using a spectrometer with an integrating sphere and a back-thinned CCD detector. Phys. Chem. Chem. Phys. 11, 9850-9860 (2009).

38 Frisch, M.J. et al. Gaussian 09, revision D. 01. Gaussian, Inc., Wallingford CT (2009).

39 Dreuw, A., Weisman, J.L. \& Head-Gordon, M. Long-range charge-transfer excited states in time-dependent density functional theory require non-local exchange. J. Chem. Phys. 119, 2943-2946 (2003).

40 Jacquemin, D. et al. Assessment of the efficiency of long-range corrected functionals for some properties of large compounds. J. Chem. Phys. 126, 144105 (2007). 
41 Guthmuller, J. \& Champagne, B. Resonance Raman scattering of rhodamine 6G as calculated by time-dependent density functional theory: vibronic and solvent effects. $J$. Phys. Chem. A 112, 3215-3223 (2008).

42 Setiawan, D., Kazaryan, A., Martoprawiro, M.A. \& Filatov, M. A first principles study of fluorescence quenching in rhodamine B dimers: How can quenching occur in dimeric species? Phys. Chem. Chem. Phys. 12, 11238-11244 (2010).

43 Mütze, J. et al. Excitation spectra and brightness optimization of two-photon excited probes. Biophys. J. 102, 934-944 (2012).

44 Akerboom, J. et al. Optimization of a GCaMP calcium indicator for neural activity imaging. J. Neurosci. 32, 13819-13840 (2012).

45 Schindelin, J. et al. Fiji: an open-source platform for biological-image analysis. Nat. Methods 9, 676-682 (2012).

46 Ohyama, T. et al. A multilevel multimodal circuit enhances action selection in Drosophila. Nature 520, 633-639 (2015).

47 Ji, N., Milkie, D.E. \& Betzig, E. Adaptive optics via pupil segmentation for highresolution imaging in biological tissues. Nat. Methods 7, 141-147 (2010).

48 Sun, W., Tan, Z., Mensh, B.D. \& Ji, N. Thalamus provides layer 4 of primary visual cortex with orientation- and direction-tuned inputs. Nat. Neurosci. 19, 308-315 (2016). 